DOI: 10.23860/JMLE-2019-11-2-2

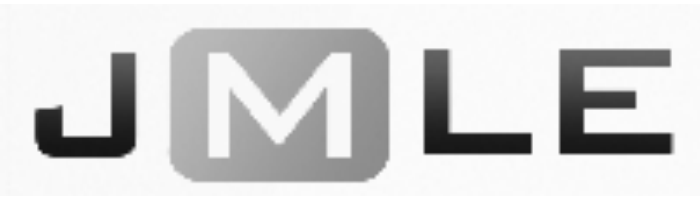

The National Association for Media Literacy Education's

Journal of Media Literacy Education 11 (2), 20 - 36

\title{
Media Literacy Education in the Age of Machine Learning
}

\author{
Teemu Valtonen \\ University of Eastern Finland, Finland \\ Matti Tedre \\ University of Eastern Finland, Finland \\ Kati Mäkitalo \\ University of Oulu, Finland \\ Henriikka Vartiainen \\ University of Eastern Finland, Finland
}

\begin{abstract}
The media environment has radically changed over the past few decades. Transition and transformation of media platforms has enabled algorithms and automation to take over media processes such as production, content generation, curation, delivery, recommendation, and filtering of information. It has also enabled tracking of users' actions, data mining, profiling, and the use of computational and machine learning techniques for purposes like behavior engineering, targeted advertisement, spread of mis- and disinformation, swaying political moods, and many others. In the field of media literacy education, the need to understand algorithm-driven media requires educators to re-think the connections between media literacy education and computing education. This article provides an overview of some computational mechanisms of today's media, and it provides new perspectives for media literacy education. The article suggests ways of intertwining media literacy education with computing education in order to improve students' readiness to cope with modern media and to become critical and skilled actors to navigate in the today's media landscape.
\end{abstract}

Keywords: Media literacy, Social media, Machine learning, $21^{\text {st }}$ century skills, ICT literacy, Critical thinking

\section{INTRODUCTION}

Today's students are expected to have so-called $21^{\text {st }}$ century skills necessary for the contemporary society and working life (Voogt \& Roblin, 2012). These skills highlight the role of new technology as a provider of tools for various purposes, and it also emphasizes the skills and knowledge for understanding and coping with the effects that new technology has on societies. There are various definitions of 
the $21^{\text {st }}$ century skills, emphasizing collaboration, communication, ICT skills, information/media literacy, social and/or cultural competencies, creativity, critical thinking, and problem solving (Mishra \& Kereluik, 2011; Voogt \& Roblin, 2012). This article focuses on areas of $21^{\text {st }}$ century skills related to media literacy, ICT skills, and critical thinking.

Over the past decade, there have been major shifts in the convergence of technology and media. Ubiquitous ICT has become a reality and cloud computing has realized the 1960s dream of "computer utility" similar to running water and electricity. Myriads of gadgets, applications, and services provide help and support to various everyday life situations, from navigation, real-time translation, and shopping to watching news, learning new skills, and finding a partner. One central set of "web 2.0" tools are the social media: a large number of different user-driven communication services like Facebook, WhatsApp, Twitter, YouTube, and Instagram (e.g., Obar \& Wildman, 2015). Social media is becoming increasingly important as a means to gain information about the world, competing with traditional media sources.

Many forms of new technology, including social media, are based on massive data collection. They rely on their users producing vast amounts of rich, unstructured data in different formats-location data, pictures, pieces of text, information about their moods, the music they are listening to, movies they are watching, goods they are shopping, and so forth (e.g., Kelly, 2017). That rich data provide better services for customers by, for example, offering less congested driving routes, suggesting restaurants, or recommending movies. Many services would not work without a steady stream of data from large crowds of other users. At the same time, the same data are used for political ends, advertisement, or behavior engineering (e.g., Kramer, Guillory, \& Hancock, 2014). Most services use authentic data generated by users in their everyday activities and communication, which makes that data greatly different from traditional research data collected through instruments like interviews or questionnaires, and those services typically do not meet the "informed" part of informed consent (Tufekci, 2015).

The possibilities and challenges related to today's technology and media pose new demands for education. In addition to media literacy education, since the 1960s much has been done to further education in the digital age under initiatives like computer literacy, fluency with ICT, and coding literacy, which often boil down to programming (Guzdial, 2015; Vee, 2017). Vee's (2017) and Guzdial's (2015) analyses of those initiatives show how they have attempted to redefine technology education over the past 30 years. None of them do, however, capture the essence of the technology revolution that has shaken the world since the 2000s, especially the changes related to media, and how the nature of media and news has changed.

The great technological shift of the 2000 s, which also greatly affected the media landscape, was the shift from rule-driven programs-where rules for program behavior were explicitly hand-coded by hordes of programmers - to datadriven programs-where program behaviors are automatically derived from massive amounts of data. The technology of the "second machine age" (Brynjolfsson \& McAfee, 2014) is mostly of the latter kind: image recognition, 
speech recognition, machine translation, self-driving cars, and many, if not most, other transformative technologies are based on neural networks and machine learning and not on traditional programming (Karpathy, 2017). What is more, the concerns with massive shifts in employment that fuel "coding for kids" initiatives are almost all based on a data revolution, not a programming revolution. Programs that can predict people's behavior better than their spouses can, or know when one is pregnant or about to lose a job, are all data-driven, and all of them use relatively standard statistical algorithms available in ready-made program libraries. Driver jobs lost to self-driving cars are not replaced by programmer jobs to program those cars: the cars use machine learning algorithms. In the context of targeted media, Cambridge Analytica used tens of millions voter profiles to affect elections. Billions of sensors produce exabytes $\left(10^{18}\right)$ of data every day, and much of that ends up being analyzed and used for purposes users do not know about. These new opportunities have also resulted in dramatic effects on media and news. The mechanisms of media have changed, and instead of offering the same news for everyone, produced by the editors, reporters, and fact checkers, with today's technology media and news can be targeted for certain groups of people for certain purposes. In terms of education, understanding how this media work is important as it exposes the mechanisms of the virtual spaces people inhabit.

The possibilities of technology have made media literacy education more important than ever. Still, while much has been written about the 21 st century skills, media literacy, coding literacy, and ICT literacy, none of them, on their own, provide students with adequate knowledge and tools to understand or deal with the mechanisms behind today's media and how data-driven technology is used for a multitude of purposes - such as curate and create content, affect people's behavior, create echo chambers, sway elections, and so on. This article presents ways to support students' skills to meet these challenges by first outlining trends of today's media technology, and then providing technological perspectives for media literacy education. The curriculum examples come from Finland, but the topics are to a great extent applicable to industrialized countries in general. We first outline the technical shifts that have enabled the machine learning revolution in media, and then describe some directions for providing students with knowledge that can help them better understand the mechanisms of the media.

\section{DEMOCRATIZATION OF MEDIA}

The first issues that media literacy will need to address are concerned with the new dynamics of creating content that is circulated in the social media and often accepted as facts, and what kinds of behavior engineering or attention engineering are used to affect social media users. This chapter discusses the new forms of media automation, mis- and disinformation, and ways in which new technologies are used to collect user data and to target and tailor certain media content for individuals or groups. 


\section{Social Media: Shift from Factual Disagreements to Emotion Farming}

New technologies have opened up new possibilities for traditional media and created new kinds of media altogether. Today's world has been described as a "post-truth" era, one in which "objective facts are less influential in shaping public opinion than appeals to emotion and personal belief" (post-truth, 2019). The concept of post-truth is not new, but the term has become popular via the British "Brexit" vote and the 2016 US presidential election (Modreanu, 2017). The difference between fact and fantasy has been blurred by technologies that make media consumers into producers and distributors, that aggressively filter and curate content, and that enable anonymity and undermine accountability, just to name a few (Modreanu, 2017). New technologies have made the production, dissemination, and targeting of mis- and disinformation easy, cheap, and effective. What is more, in platforms where media followers and producers can be bots, everything else can be fake, too.

The old but lately fashionable word "fake news" has several definitions. Allcott and Gentzkow (2017, p. 13) defined fake news as "news articles that are intentionally and verifiably false, and could mislead readers". Gelfert (2018, p. 84) defined it as "deliberate presentation of (typically) false or misleading claims as news, where the claims are misleading by design". Lazer et al. (2018, p. 1094) defined it as "fabricated information that mimics news media content in form but not in organizational process or intent." Typical for fake news is that they are designed to look like real news in order to mislead people, while the process of fake news production differs from the traditional news. With fake news reporters, editors, and fact checkers are not needed, but instead a small group of people, even single persons or algorithms, can create large numbers of fake news for various purposes. According to Vargo, Guo, and Amazeen (2018), many fake news related to presidential election in the United States were produced by individual people from Eastern Europe in order to make money. Fake news often mimic real news in order to make them look more credible. For this purpose, fake news can be supported with manipulated pictures or manipulated videos to make them more believable (e.g., Tandoc Jr, Lim, \& Ling, 2018).

One of the reasons fake news has become a buzzword again is that new technology facilitates them in a number of ways, ranging from their improved credibility to their dynamic creation and effective dissemination. According to Vosoughi, Roy, and Aral (2018) fake news spread faster than more traditional, "fact based" news - although not just because of automation, but also because of social engineering. Fake news are often designed to be provoking, sensational, or interesting in order to intrigue people and to gain maximal attention and coverage. Using a combination of data mining and adaptive media, social media providers attempt to maximize the time their users spend on their platforms, and machine learning algorithms often learn that provoking and polarizing news guarantee the highest time spent on media. What is more, those news spread to mainstream media, too: Vargo, Guo and Amazeen (2018) refer to the "agenda setting power" of fabricated news to push topics into other online media. Coping with the world of algorithmically created and distributed news is a challenge to existing media literacy education. 
Even when the stories are known to be fictitious, they occasionally trigger discussions among broader audiences. Hendricks and Vestergaard (2019) argued that more attention means more credibility, known as "social proof." In order to increase the credibility of manufactured stories, software-based automation is used to increase the visibility of those stories: in December 2018 the going rate for five thousand (fake) social media followers is US\$39.99. Bots are able to mimic human discussions and human actions and make them less easily identifiable as bots. Whilst propaganda, misinformation and disinformation have a long history, new technology has provided new ways of deception, behavior modification, and global dissemination.

The effects of disinformation can be long lasting. Hendricks and Vestergaard (2019) used the phrase "belief echo" to refer to that long effect. In cases where social media posters have made false claims about people, political topics, or commercial concerns, through the belief echo they continue to influence people's opinions and perceptions of the topic for a long time-even when those claims are shown to be fabrications (Hendricks \& Vestergaard, 2019). What is more, through automated content curation, content recommendation, and filtering, social media can create echo chambers, where users' personal interests and beliefs are amplified by an endless stream of content that resonates with them-be it true or false. With the lack of content to challenge users' views, echo chambers facilitate homogenous social networks and attitudinal polarization (Lazer et al., 2018). The emergence of echo chambers vary between social media, based on their mechanisms of network formation (Bakshy, Messign, \& Adamic, 2015). The mechanics behind these phenomena are not exceedingly complex, but knowledge about them is vital for navigating the media: Traditional media literacy education offers some, but not all, means for that.

\section{Social Media: Invisible Attention Engineering}

The traditional process of newsmaking is a "glass box" process in the sense that the players in the newsroom, their tasks, and each step in the process from content gathering to delivery can be made transparent and can be, in principle, traced, analyzed, understood, and criticized. Due to their one-to-many broadcasting model of delivery, every "old" media consumer got the same content. Neither of the above holds true in the algorithm-driven social media, web 2.0, and internet of things. Firstly, many newer algorithmic solutions are "black boxes" in the sense that it is in practice impossible to trace why an algorithm-driven or neural network-driven system does what it does. The algorithms that run online media platforms are well-hidden secrets of companies who own them. What is more, although the algorithms themselves are deterministic - they always arrive at the same results from the same inputs and states - they have practically infinite combinations of internal states and external inputs, and especially in the case of neural networks, it is usually practically impossible to know "why" the system arrived at its results.

Secondly, in the case of adaptive, dynamic, and personalized newsmaking, each user gets their personal media feed tailored for them, instead of editors choosing broadcasted contents for everyone (Tufekci, 2015). Algorithms filter, 
highlight, or suppress contents shown to the users, providing the users the media contents they find most relevant and engaging (Kramer, Guillory, \& Hancock, 2014). What is more, newer algorithms create unique content to cater to each user's personal preferences. Techniques sometimes called "attention engineering" or "behavior engineering" are used to maximize the time users spend on the companies' platforms. For example, Kramer, Guillory, and Hancock (2014) demonstrated a massive scale experiment, which showed that by filtering and modifying social media newsfeeds it is possible to manipulate people's emotions without their awareness. Through similar techniques, news, advertisement, radio stations, bots faking as people, and all kinds of digital content and agents can be created and personalized at an individual level and used for improved services, doing various jobs, behavior engineering, and many other types of activities. The consent for applying users' tracking data for those purposes is obtained from enduser license agreements that users must accept in order to use web 2.0 services (Tufekci, 2015).

The data needed for adaptive media content, attention engineering, and all other personalized services come from unobtrusive tracking of users' public or private activities instead of traditional questionnaire or interview based research (e.g., Tufekci, 2015). For instance, one study evaluated how many Facebook "likes" the computer needs to observe in order to accurately judge people's personalities on the Big Five personality test (Youyou, Kosinski, \& Stillwell, 2015). After observing 10 likes, the computer judged a person more accurately than his or her colleagues did, after 70 likes the computer outperformed cohabitants and friends, after 150 it outperformed family members, and after 300 it outperformed spouses (ibid.) Another machine learning study analyzed tweets to correctly predict people's political alignments with 91\% accuracy (Conover, Gonçalves, Ratkiewicz, Flammini, \& Menczer, 2011). A subsequent machine learning study correctly identified people's sexual orientations in $88 \%$ of cases and ethnic group in $95 \%$ of cases (Kosinski, Stillwell, \& Graepel, 2013), and the more data, the better the prediction. Few things remain secret in social media.

Tracking of users' actions is the driver of many useful services: the more information about the user, the better the services provided and the more time users spend on those services (Kelly, 2017). Tracking involves, among other things, data from people's use of social media and web 2.0, location data from their smartphones, their consumption habits from loyalty programs, smart homes, security cameras, and fitness trackers that measure heart beat, diet, and sleep-just to mention a few (e.g., Kelly, 2017). The "smartness" of smart devices arises from their programming and from the massive amount of data available to the programs. Yet, the same information that is used for improved personalized services can be used for advertising, targeting fictitious content, or other kinds of behavior engineering. The Cambridge Analytica system that allegedly influenced the 2016 US presidential election mined user data to create personality profiles of tens of millions of users and created personalized advertisement based on an assessment of how those users might best be swayed. In a study targeting 61 million people, Bond et al. (2012) showed the possibility to use social media to influence people's political self-expression, information seeking, and their real world voting 
behavior. Altogether, these studies show how machine learning, big data, and social media analytics can be used in ways that were previously impossible, posing questions about the extent to which knowledge about them is important for the domain of media literacy education.

\section{CURRENT RESPONSES-MEDIA LITERACY AND COMPUTATIONAL THINKING}

The above features of algorithm-driven social media demand very specific skills and competences from the people involved. Understanding the mechanisms that drive today's media would be important for more critical media consumption that better acknowledges the uses and possibilities of algorithm-driven media technology. The concerns presented in the previous section pose challenges for educational attempts in terms of what kinds of skills and knowledge students need to cope with targeted news and manipulation attempts. As Lazer et al. (2018) noted, organized education is a central channel for improving individuals' skills to cope with new information sources and for providing them with readiness to evaluate different information sources and news. Hobbs and McGee (2014) put it more bluntly, suggesting a need to develop a sense of "crap detection". Each of the challenges in the previous section emphasize the importance of media literacy, but it is unclear what kind of media literacy would that be and how it should be addressed in education.

\section{Media Literacy in the Age of Machine Learning}

The phrase "media literacy" has been defined in many different ways, each emphasizing different aspects of it. One oft-quoted definition is by Aufderheide (1993, p. 6): "ability of a citizen to access, analyze, and produce information for specific outcomes". More recently, Chu and Lee (2014) have referred to media literacy as a life skill for especially young people to critically understand, analyze, and influence the media. Bulger and Davison (2018) described media literacy as skills that support critical engagement with information presented by the media, providing ways to cope with fake news. According to one view, media literacy education focuses on creating "watchful buyers," "skeptical observers," and "wellinformed citizens" (Hobbs, 2012). Lim and Nekmat (2008) defined a media literate person as one who is aware of the effects of media for individuals, and why certain news contents are amplified and others are excluded.

In broader terms, media literacy is often considered a prerequisite for participation in today's society (cf. Martens, 2010). Potter (2013) outlined three key issues in media literacy: First, media literacy should focus on all forms of media. Second, media literacy should be seen both as skills and as knowledge. The skills for critical thinking are highly important and emphasized in different definitions of media literacy. In addition to skills, knowledge about the effects of the media, how media works, and how media can affect people, are crucial elements of media literacy. Third, media literacy should improve the lives of the people, provide them with more control over the media and how media affects their lives, 
and increase people's awareness of the effects of media. Achieving these three key issues face new challenges in the new, algorithm-driven media environments.

A number of definitions of media literacy strongly emphasize critical thinking (Potter, 2013). As an old concept, critical thinking has been defined in many ways, such as "reflective and reasonable thinking that is focused on deciding what to believe or do" (Norris, 1985, p. 45) and as "reflective and reasonable thinking that is focused on deciding what to believe or do" (Ennis, 1985, p. 45). Both those definitions focus on reflective thinking about decision-making and epistemological commitment on what to believe. Critical thinking has been actively promoted as one of the $21^{\text {st }}$ century skills (Voogt \& Roblin, 2012). It has typically been linked with problem solving (Voogt \& Roblin, 2010) as a skill that guides towards making the right decisions. In a $21^{\text {st }}$ century skills questionnaire by van de Oudeweetering and Voogt (2018) critical thinking was measured by statements like "compare information from different sources," "formulate one's own judgment or perspective," and "support one's own opinion with arguments."

Based on changes in media described in section two, especially with the new possibilities and influence of algorithm-driven media, the importance of media literacy education and critical thinking increase. Martens (2010) outlined the horizon of media literacy and argued that today's body of research still contains relatively little about actual media literacy education practices in schools. The USbased National Association for Media Literacy Education (NAMLE, 2018) defined six core principles for media literacy education. These principles emphasized individuals' active inquiry and critical thinking, and they affirmed the importance of people's skills, beliefs, and experiences for building their own meanings from media contents. The aim of media literacy education is to train informed, reflective, and engaged participants for a democratic society. Media need to be seen as part of the culture, media refer to all different kinds of media, and media literacy education needs to be provided for all age groups.

A variety of online resources provide concrete descriptions of learning activities in media literacy education. For example, Center for Media Literacy (http://www.medialit.org/) provides activities and material for supporting media literacy education at different levels of education. Similarly, NAMLE provides various types of materials, exercises, and activities for media literacy education. International Federation of Library Associations provides eight-step guidelines for spotting fake news. Those guidelines focus on who wrote the news (the author(s) and the source), what is the whole story behind the headline, what additional material and sources support the news, when was it published, whether the news is a joke, whether it is believable, and whether an expert consultation could shed more light on the news (IFLA, 2018).

Many countries have included media literacy in their $\mathrm{K}-12$ curricula. In Finnish education, for example, aims similar to those above are embedded in national curricula for elementary and upper secondary schools (FNBoE, 2014; 2015). The Finnish core curricula introduce media literacy (and more generally the mechanisms and effects of today's media) in a variety of contexts. Curricula for elementary and upper secondary levels contain so-called transversal competence, referring to entities of knowledge, skills, values, attitudes, and volition that need to 
be a part of everyday teaching and learning practices and content in schools. Skills relevant to media literacy education in the era of social media cross-cut the curricula. Some relevant competences are found, for instance, under "multiliteracy" and "ICT competence" (FNBoE, 2014, 2015). Multiliteracy is closely related to the concept of media literacy (Palsa \& Ruokamo, 2015); it aims at supporting the development of pupils' critical thinking and it highlights the skills to make value judgements across variety of different texts, and to interpret and produce texts using current technologies and multimodal techniques. ICT competences are seen as today's civic skills in terms of basic use of ICT; responsible, safe, and ergonomic use of ICT; use of ICT for information management and for exploratory and creative work; and use of ICT for interaction and networking.

To continue the example of Finnish schools, the cross-cutting themes above are included in three subjects in Finnish schools (FNBoE, 2014). One aim of the Finnish language and literature curriculum is to provide students the skills for analyzing, assessing, and interpreting diverse texts, to understand that different texts have different goals and purposes, and to use different information sources and to evaluate the reliability of information. One aim in the social studies curriculum is to prepare pupils to use media as a way to participate in societal activities. Students are encouraged to follow topical issues and events, analyze how those issues and events affect their own lives, and to critically assess information produced by various actors. One aim of the mathematics curriculum is to provide pupils ICT competences, including readiness for programming and skills for algorithmic thinking.

Areas of media literacy and multiliteracy provide important knowledge and skills for students. Still, in order to gain the abilities for critical thinking and media literacy in the age of media automation, media literacy education and computational thinking have to be tightly intertwined in education. It is not possible for individuals to critically evaluate what they see on their newsfeeds and social networks without understanding some principles of the underlying algorithmic processes. Instead of the old "glass box" processes of news making, invisible attention engineering and content creation processes demand additional perspectives to and new contents for media literacy education. These new contents can be grounded in the elements of computer science. By providing students with more information of the invisible, they gain better readiness for being critical consumers of information; they become more media literate.

\section{ICT Literacy}

Today's attempts to strengthen computing education in schools is by no means a new idea. A vision of computing's importance for general education arose early on in the history of computing (Guzdial, 2015). Already in the late 1950s there arose a sentiment that computing is a skill useful for all kinds of subjects (e.g., Forsythe, 1959; Perlis as quoted in Katz, 1960). In the first decades of modern computing, from the 1950 s to 1960 s, computing education was primarily the purview of higher education institutions, and $\mathrm{K}-12$ educational initiatives were few and far between. A number of pioneering initiatives for teaching computing in schools did arise, among them the Little Man Computer instructional model of 
computers, the Dynabook laptop computer for children, and the Logo programming language for education (Guzdial \& Boulay, 2019; Denning \& Tedre, 2019). Yet, aside from Logo, none of them succeeded to bring computing to $\mathrm{K}-12$ schools at a large scale. The first attempts to introduce computing to $\mathrm{K}-12$ schools were typically focused on programming. Some of them were very ambitious and caught educators' attention across disciplinary boundaries. Most famously, Seymour Papert's 1980 book Mindstorms, which was based on over a decade's worth of research by a group of people, presented computing as a way to think about problems and about solving them.

As large-scale roll-outs of bringing programming to $\mathrm{K}-12$ schools faltered for various reasons, starting from a severe lack of teachers who knew programming, the balance shifted to "computer literacy" courses (Denning \& Tedre, 2019). Computer literacy was conceived as skills of using computer programs and applications, including word processing, basic databases, sketchpads, and rudimentary expert systems. In the late 1990s literacy was upgraded to fluency, and paired with learning material and a popular textbook Fluency with Information Technology. Yet, even when supported by greatly improved user interfaces, welldesigned languages, better hardware, increased automation, and pedagogical advances, programming in schools remained a curiosity. While the society was becoming increasingly dependent on computing technology, its underlying mechanisms were still not widely taught in schools.

The latest wave of bringing computing to schools started in 2006, with the K-12 computing education catchphrase "fluency" being replaced by "computational thinking" (Wing, 2006; Guzdial, 2015; Denning \& Tedre, 2019). Now the time was ripe for action: parents, policymakers, politicians, and teachers were all experiencing the computer revolution first hand, and were eager to support bringing computing education to schools (Mannila et al., 2014). Many initiatives, however, deliberately avoided historically loaded and stereotypical words like "computer science" and "programming," and chose to use "computational thinking" instead (Mannila et al., 2014). In our example Finnish context, the national curriculum designers chose to integrate computational thinking in all subjects instead of introducing computing as a new compulsory or elective subject. However, a recent national survey showed that majority of teachers do not have the requisite skills for integrating computational thinking in their own subjects (Kaarakainen et al., 2017). In many educational contexts, computing is considered a cross-cutting skill that should be integrated in all subjects that make use of modern ICT technology.

\section{New Themes for Media Literacy}

Insofar as understanding media requires understanding some of its underlying technology, and insofar as understanding disciplinary mechanics of computing should be integrated in school subjects, also media literacy education needs some computational content. What that content should be is, however, an open question. The descriptions of media and media literacy in the above sections are often loose and can, in principle, contain items like basic understanding of the mechanisms of machine learning, automatic analysis and generation of news, 
autonomous interactive agents (bots), behavior modification, adaptive and personalized media, revenue optimization, and behavior/attention engineering. However, these themes are typically not included in media literacy education, not even under the mechanisms of todays' media or how today's algorithm-driven media works. The following table (Table 1), shows examples of technologies that greatly affect the dynamics of today's media, that are vital for media literacy in the age of machine learning, and that are candidates for inclusion in media literacy education.

Table 1.

Technologies for media literacy

\begin{tabular}{ll}
\hline Technology & Educational themes and content \\
\hline Tracking & How are people tracked in the physical world (phones, health \\
& devices, instagram photos with geolocation data, credit cards, \\
& utilities, security surveillance, etc.) as well as in virtual worlds \\
& (twitter posts, facebook face recognition, loyalty cards, \\
& software updates, calendar events, etc.) - and how these are \\
& combined to make an extremely accurate profile of you, the \\
& consumer.
\end{tabular}

Recommenders How do recommender systems use tracking data from massive and numbers of people to very accurately predict what you might optimization be interested in, based on people with similar interests, as well as on content similarity - and how is that information used for marketing, political and social purposes, provision of instant gratification, and facilitating addictive behavior.

$\begin{array}{ll}\begin{array}{l}\text { Dynamic } \\ \text { content }\end{array} & \text { How is natural language generation used, for example, to create } \\ \text { generation } & \text { large farms of "followers" in social media, to create news and } \\ & \text { fake news that appeal to users' interests, to design bots that are } \\ & \text { able to carry out conversations, and to automate journalism. }\end{array}$

Deep learning How do computers learn to do tasks by looking at large numbers of examples; tasks such as translate text between languages, spot fraudulent credit card transactions, paint or compose music in specific styles, and recognize faces, speech, or objects in photos.

Reinforcement How do computers learn, by themselves, to take the right learning actions in complex, unstructured environments, such as keep up a conversation, drive a car, land a plane, learn to play games better than people do, find optimal settings for media content and customer retention, and optimize logistical operations. 
Attention engineering
How are social media adapting and tailoring their content to maximize the time users spend on their services through, for example, amplifying negative emotions and excitement, magnifying polarization, and finding an optimal balance between gratification and unpredictability.

\section{Content}

filtering/ curation
How do web 2.0 platforms learn to curate content that the user is most likely to click or to filter content that is likely to drive the user away; for instance, search engines and video-sharing websites adapting to the user's earlier choices, and newspaper comment sections filtering out potentially offensive or objectionable comments.

The aim of this article is not to incite fear or skepticism toward social media, automated journalism, machine learning, or other forms of new technology. Rather it is to raise awareness of some central new techniques that greatly influence today's new forms of media. Table 1 lists broad areas of technology and relates them to specific jobs each technology is used for in the context of media. These areas are some of the drivers of today's media, and awareness of their existence is important for media literacy.

From the perspective of merging media literacy education and computing education, the areas outlined in Table 1 can be taught at different levels of abstraction, starting from a level where no familiarity with algorithms or computational thinking is needed, and ending at a level that requires sophisticated coding skills or statistics. Our suggestion is to provide students with perspectives to technologies in Table 1 in the context of broader media literacy education, combined with some basic computational thinking - yet no programming needs to be involved. The aim is to provide students with insights into how each technology listed in Table 1 influences them personally. By doing that we wish to open the algorithmic black box so that students can understand the mechanisms driving their own social media interfaces and newsfeeds.

An important aspect in our approach is to acknowledge the central role of tracking, or ubiquitous collection of users' everyday actions into massive databases that can be combined in endless number of ways. Students can be asked to list all services they use daily and what kind of data can be extracted from their actions in each. They can create hypothetical profiles of themselves based on that data to reveal how intimately programs can know their habits and personalities. This enables students to think of the positive and negative impacts that allowing different services to collect and use their data can have. Decreased privacy is often the flip side of improved services. Furthermore, students can reflect on the terms and conditions of different services they use. By reading through the terms and conditions of Facebook, Google, Snapchat, or other services, one can better understand what can be done with the data and the tracks they leave behind, and how this data can be used for profiling.

There are also other important lessons regarding privacy that media literacy should incorporate. It is important to explain how tracking gives companies not only the tools for profiling their users ("I know what you did last summer"), but 
that when combined with the data of millions or billions of users, it also provides the tools for very accurately predicting users' next actions ("I know what you will do next summer") (Krishnamurthy, 2010). Anonymity, one of Internet's early virtues, is also all but gone in the era of ubiquitous tracking; given enough data resolving "anonymous" identities becomes a trivial task.

In order to help students to understand why they are offered the content they see, as well as the possibilities of recommenders, user profiling, and targeted content, students can be given a task where they can analyze a set of fictitious profiles with rich tracked data about them-such as age, gender, personality, hobbies, movements on the map, Netflix history, "likes", google searches, and friends. Students can then analyze those mock profiles and plan what news, media, political, or commercial content they could sell to the person. The aim would be to help students to better understand how seemingly innocuous pieces of data can be pooled together to form accurate, rich profiles of users, without the user knowing it. Again, the aim would be to think who or what parties would find these profiles important, who could benefit from them, and instill a realistic picture of how their own content is being tailored for them-for their benefit but also for the benefit of others.

For a concrete example of how quickly systems pick up users' preferences, students can be asked to use YouTube on different computers, click open certain kinds of content (e.g., gaming-related videos, left- or right-wing politics, and cute animal videos), and observe how fast each of them are fed just one kind of material, essentially creating their echo chambers on the fly. The same can be tried on Google and Amazon, for example, and also compare the students' results with a blank history. The aim is to demonstrate the difference between results when the search engine is providing the user with targeted content and what would the results be without profiling.

In order to cope with rapid technological change in media production and consumption, there is a need to combine the more established areas of media literacy education with knowledge of basic techniques driving the media today. Table 1 is by no means an all-encompassing listing of data mining and behavior engineering techniques; rather we suggest it as a starting point for discussing ways to make the mechanisms behind the media more visible and more understandable for students. In the context of Finland, the national curricula emphasize phenomenon-based learning, whereby the learning process is built around larger real world phenomena that require combining different subjects, instead of teaching each subject separately (FNBoE, 2014). Adopting this approach provides a context for intertwining media literacy education with technology education, and to study media related topics using the perspectives listed in Table 1. Similarly, the different areas in Table 1 can be combined into larger projects that analyze today's media world from different perspectives and combine technology education with media literacy education. Altogether, media literacy fostered with computing perspectives would provide students with deeper perspective of media, tools for critical analysis of modern media, and understanding of how and why certain contents are provided for them. 


\section{CONCLUSION}

Media literacy education is highly important in the era of media driven by brilliant technologies. With new technology the production, dissemination, and targeting of mis- and disinformation, advertisement, political and commercial content, and all other kinds of content is easy, cheap, and effective. Today's algorithm-driven media is a powerful tool for profiling people, predicting their actions, and influencing people in different ways for different purposes. In order to foster media literacy education by teaching the tools used in today's media, it is important to add a number of powerful ideas from computer science, especially machine learning, as part of media literacy education. Basic knowledge of the computing mechanics outlined above would give the students the basic skills and knowledge for recognizing and evaluating the impact of new technology in different situations and contexts. Understanding the practices of media provides students with better tools for critical thinking and for understanding different motives, purposes, and uses of media. This is also important from a societal point of view, to understand how echo chambers are formed, emotions amplified, and behavior engineered - and through them how products are sold, elections swayed, and mass movements born.

This article provides technical perspectives to the discussion of media literacy education. It also suggests ways to integrate these perspectives in media literacy curricula in order to provide students with skills needed in today's media environment. However, these ideas pose challenges for curriculum design and for teachers and teacher collaboration. Media literacy and computer science are both important entities per se, but the merger of media and technology has made it necessary to bring them also together across disciplinary boundaries in education, too.

\section{REFERENCES}

Allcott, H., \& Gentzkow, M. (2017). Social media and fake news in the 2016 election. Journal of Economic Perspectives, 31(2), 211-36.

Aufderheide, P. (1993). Media literacy. A report of the National Leadership Conference on Media Literacy. Aspen Institute, Communications and Society Program, 1755 Massachusetts Avenue, NW, Suite 501, Washington, DC 20036.

Bakshy, E., Messing, S., \& Adamic, L. A. (2015). Exposure to ideologically diverse news and opinion on Facebook. Science, 348(6239), 1130-1132.

Bond, R., Fariss, C., Jones, J., Kramer, A., Marlow, C., Settle, J., \& Fowler, J. (2012). A 61-million-person experiment in social influence and political mobilization. Nature, 489(7415), 295.

Brynjolfsson, E., \& McAfee, A. (2014). The second machine age: Work, progress, and prosperity in a time of brilliant technologies. W. W. Norton \& Company, New York, NY, USA.

Bulger, M., \& Davison, P. (2018). The promises, challenges, and futures of media literacy. Data \& Society, 21 February 2018. 
Chu, D., \& Lee, A. (2014). Media education initiatives by media organizations: The uses of media literacy in Hong Kong media. Journalism \& Mass Communication Educator, 69(2), 127-145.

Conover, M., Gonçalves, B., Ratkiewicz, J., Flammini, A., \& Menczer, F. (2011). Predicting the political alignment of Twitter users. In Proceedings of the 2011 IEEE Third International Conference on Privacy, Security, Risk and Trust (pp. 192-199), Boston, MA.

Denning, P., \& Tedre, M. (2019). Computational thinking. The MIT Press, Cambridge, MA, USA.

Ennis, R. (1985). A logical basis for measuring critical thinking skills. Educational Leadership, 43(2), 44-48.

FNBoE. (2014). National core curriculum for basic education 2014. Helsinki: Finland: Finnish National Board of Education.

FNBoE. (2015). National core curriculum for general upper secondary schools 2015. Helsinki, Finland: Finnish National Board of Education.

Forsythe, G. (1959). The role of numerical analysis in an undergraduate program. The American Mathematical Monthly, 66(8), 651-662.

Gelfert, A. (2018). Fake news: A definition. Informal Logic, 38(1), 84-117.

Guzdial, M. (2015). Learner-centered design of computing education: Research on computing for everyone. Synthesis lectures on human-centered informatics. Morgan \& Claypool, San Rafael, CA, USA.

Guzdial, M., \& du Boulay, B. (2019). The history of computing education research. In S. A. Fincher, \& A.V. Robins, (Eds.), The Cambridge handbook of computing education research (pp. 11-39). New York, NY, USA: Cambridge University Press.

Hendricks V. F., \& Vestergaard M. (2019). Reality lost: Markets of attention, misinformation and manipulation. Springer Open, Cham.

Hobbs, R. (2012). The blurring of art, journalism, and advocacy: Confronting 21st century propaganda in a world of online journalism. ISJLP, 8, 625.

Hobbs, R., \& McGee, S. (2014). Teaching about propaganda: An examination of the historical roots of media literacy. Journal of Media Literacy Education, 6(2), 5.

IFLA. (2018). How to spot fake news. Retrieved from https://www.ifla.org/publications/node/11174

Kaarakainen, M., Kaarakainen, S., Tanhua-Piiroinen, E., Viteli, J., Syvänen, A., \& Kivinen, A. (2017). Comprehensive school digitalisation: Status review and recommendations for action for 2017. Publications of the Government's Analysis, Assessment and Research Activities (72/2017). Prime Minister's Office, Helsinki, Finland.

Karpathy, A. (2017). Software 2.0. In Medium.com, https://medium.com/@karpathy/software-2-0-a64152b37c35

Katz, D. (1960). Conference report on the use of computers in engineering classroom instruction. Communications of the ACM, 3(10), 522-527.

Kelly, K. (2017). The inevitable: Understanding the 12 technological forces that will shape our future. New York, NY, USA: Penguin Books. 
Kosinski, M., Stillwell, D., \& Graepel, T. (2013). Digital records of behavior expose personal traits. Proceedings of the National Academy of Sciences, 110(15), 5802-5805.

Kramer, A., Guillory, J., \& Hancock, J. (2014). Experimental evidence of massive-scale emotional contagion through social networks. Proceedings of the National Academy of Sciences, 111(24), 8788-8790.

Krishnamurthy, B. (2010). I know what you will do next summer, SIGCOMM CCR, 1-6.

Lazer, D. M., Baum, M. A., Benkler, Y., Berinsky, A. J., Greenhill, K. M., Menczer, F., ... \& Schudson, M. (2018). The science of fake news. Science, 359(6380), 1094-1096.

Lim, S., \& Nekmat, E. (2008). Learning through 'prosuming'. Insights from media literacy programmes in Asia. Science, Technology and Society, 13(2), 259-278.

Mannila, L., Dagiene, V., Demo, B., Grgurina, N., Mirolo, C., Rolandsson, L., \& Settle, A. (2014). Computational thinking in K-9 education. In Proceedings of the working group reports of the 2014 on Innovation \& Technology in Computer Science Education Conference (pp. 1-29). ITiCSE-WGR '14, New York, NY, USA. ACM.

Martens, H. (2010). Evaluating media literacy education: Concepts, theories and future directions. Journal of Media Literacy Education, 2(1), 1-22.

Mishra, P., \& Kereluik, K. (2011). What 21st century learning? A review and a synthesis. In Society for Information Technology \& Teacher Education International Conference (pp. 3301-3312). Association for the Advancement of Computing in Education (AACE).

Modreanu, S. (2017). The Post-Truth Era? Human and Social Studies, 6(3), 7-9.

NAMLE. (2018). The core principles of media literacy education. Retrieved from https://namle.net/publications/core-principles/

Norris, S. (1985). Synthesis of research on critical thinking. Educational Leadership, 42(8), 40-45.

Obar, J. A., \& Wildman, S. S. (2015). Social media definition and the governance challenge-an introduction to the special issue. Telecommunications Policy, 39(9), 745-750.

Palsa, L., \& Ruokamo, H. (2015). Behind the concepts of multiliteracies and media literacy in the renewed Finnish core curriculum: A systematic literature review of peer-reviewed research. Seminar.net, 11(2). Retrieved from https://journals.hioa.no/index.php/seminar/article/view/2354

Papert, S. (1980). Mindstorms: Children, computers, and powerful ideas. Basic Books, Inc.

Post-truth. (2019). In Oxford Dictionary. Retrieved from https://eur03.safelinks.protection.outlook.com/?url=https $\% 3 \mathrm{~A} \% 2 \mathrm{~F} \% 2 \mathrm{Fen}$. oxforddictionaries.com $\% 2$ Fdefinition $\% 2$ Fposttruth\&amp; data $=02 \% 7 \mathrm{C} 01 \% 7 \mathrm{C} \% 7 \mathrm{Ce} 19 \mathrm{f} 79 \mathrm{c} 5 \mathrm{dc} 69449962 \mathrm{cb} 08 \mathrm{~d} 6 \mathrm{f} 0 \mathrm{ca} 828$ 3\%7C87879f2e73044bf2baf263e7f83f3c34\%7C0\%7C0\%7C63696114989 7649956\&amp;sdata=SJC\%2FOmJdmXASWwZbZXUDwkDA4ZAci2qT $\underline{\mathrm{Wp} 77 \mathrm{u} 4 \mathrm{duzdk} \% 3 \mathrm{D \& amp} ; \text { reserved }=0}$ 
Potter, W. (2013). Review of literature on media literacy. Sociology Compass, 7(6), 417-435.

Tandoc Jr, E., Lim, Z., \& Ling, R. (2018). Defining "fake news". A typology of scholarly definitions. Digital Journalism, 6(2), 137-153.

Tufekci, Z. (2015). Algorithmic harms beyond Facebook and Google: Emergent challenges of computational agency. Colo. Tech. LJ, 13, 203-218.

van de Oudeweetering, K., \& Voogt, J. (2018). Teachers' conceptualization and enactment of twenty-first century competences: Exploring dimensions for new curricula. The Curriculum Journal, 29(1), 116-133.

Vargo, C. J., Guo, L., \& Amazeen, M. A. (2018). The agenda-setting power of fake news: A big data analysis of the online media landscape from 2014 to 2016. New Media \& Society, 20(5), 2028-2049.

Vee, A. (2017). Coding literacy: How computer programming is changing writing. Cambridge, MA, USA: The MIT Press.

Voogt, J., \& Roblin, N. P. (2010). 21st century skills. Discussion paper. The Netherlands: Kennisnet.

Voogt, J., \& Roblin, N. P. (2012). A comparative analysis of international frameworks for 21 st century competences: Implications for national curriculum policies. Journal of Curriculum Studies, 44(3), 299-321.

Vosoughi, S., Roy, D., \& Aral, S. (2018). The spread of true and false news online. Science, 359(6380), 1146-1151.

Wing, J. (2006). Computational thinking. Communications of the ACM, 49(3), 33-35.

Youyou, W., Kosinski, M., \& Stillwell, D. (2015). Computer-based personality judgments are more accurate than those made by humans. Proceedings of the National Academy of Sciences, 112(4), 1036-1040. 